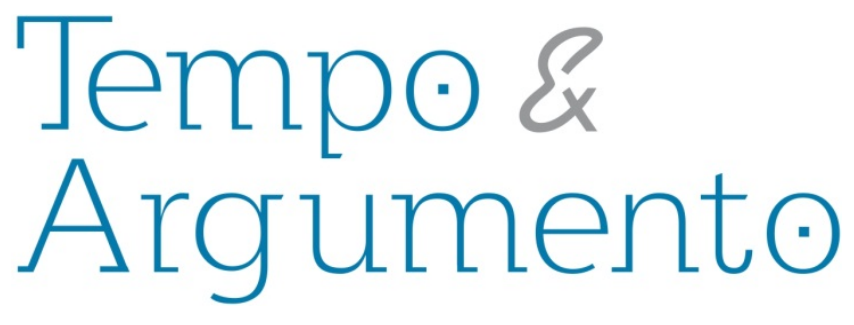

\title{
Pesquisas em história, violência e política no Chile Uma conversa com o Prof. Igor Alexis Goicovic Donoso
}

\begin{abstract}
Durante o II Seminário de História do Tempo Presente, realizamos a entrevista que segue no LABGEF/LEH com o Prof. Dr. Igor Alexis Goicovic Donoso, na qual pudemos conhecer sua trajetória como pesquisador e aspectos das atuais pesquisas realizadas no Chile e em parceria com pesquisadores latino americanos. Igor Alexis Goicovic Donoso é Doutor em História pela Universidad de Murcia, España (2005), professor titular na Universidad de Santiago de Chile na linha de História Política, com ênfase em História da violência política. Atualmente também é Diretor do Departamento de História na referida universidade. Publicou recentemente o livro Movimiento de Izquierda Revolucionaria (Ediciones Escaparate, Concepción, 2012).
\end{abstract}

Entrevista concedida em: 16/10/2014

\section{Entrevistadoras}

\section{Cristina luskow}

Doutoranda em História na Universidade do Estado de Santa Catarina UDESC. Brasil

cristina.iuskow@gmail.com

\section{Juliana Miranda da Silva}

Doutoranda em História na Universidade do Estado de Santa

Catarina UDESC. Brasil jumirandasilva@gmail.com

\section{Para citar esta entrevista:}

GOICOVIC DONOSO, Igor Alexis. Pesquisas em história, violência e política no Chile - Uma conversa com o Prof. Igor Alexis Goicovic Donoso. [Entrevista realizada em 16 de outubro, 2014]. Revista Tempo e Argumento, Florianópolis, v. 7, n. 14, p. 235 - 252, jan./abr. 2015.

Entrevistadoras: Cristina luskow e Juliana Miranda da Silva. 
Tempo e Argumento - ¿Podrías contarnos un poco acerca de su carrera académica?

Igor Alexis Goicovic Donoso - Pese a ser una persona bastante mayor (54 años), mi carrera académica no es tan dilatada; no es tan larga. Yo ingresé a estudiar el grado, Historia en este caso, en 1980, pero eso coincide con el ciclo más álgido de conflictividad política en el contexto de la dictadura militar chilena. La dictadura se ha instalado en 1973 pero los años 80 son los años de la institucionalización de la dictadura y por lo tanto estar en la universidad estudiando historia era casi un desafío a la participación política. Y yo durante ese período, en los años 80 me dedique básicamente... estudiaba, no crean que no estudiaba... (risas) pero fundamentalmente a la agitación política, a la militancia política, a la lucha contra la dictadura. Yo veía a la formación en la historia en ese momento más bien como una cosa lejana, distante, que tenía que ver con lo que en algún minuto me iba a servir para ganarme la vida, trabajar en algo; pero cuando lo pensaba, lo pensaba en un establecimiento educacional secundario, como maestro, impartiendo clase; no me veía ni como investigador, ni como académico, ni participando de congresos, ni publicando los resultados de los hallazgos de mi investigación. No era mi meta, no era mi objetivo. Mi preocupación fundamental era la política y mi preocupación mediata era en algún momento dedicarme a la docencia, a la educación secundaria. La dictadura concluyó en marzo de 1990 y dejé de militar más o menos en torno de esa misma época; y el año 1992, un profesor que yo había tenido en el pregrado (René Salinas Meza), me invitó a un programa de maestría. Me dice ... “mira, tú tienes ciertas habilidades, tienes algunas destrezas en este campo, ¿por qué no te vienes con nosotros a la maestría?". En este caso en la Universidad de Santiago de Chile (USACH), y la verdad que en ese momento a mí el tema académico se me devela... es decir "Mira esto es interesante, puede ser una buena opción". Yo ya estaba trabajando en el sistema de educación secundario, impartía clases en un liceo municipal, orientado preferentemente a estudiantes pobres y me sentía bastante satisfecho con lo que estaba haciendo, era cómodo, era grato. Yo sentía que estaba haciendo una buena contribución social; eso era importante en ese momento. Y todavía lo académico no era una cosa que me satisficiera mucho, me pareció interesante ir a la maestría, para aprender nuevas cosas; 
cosas que en el pregrado, en pleno contexto de dictadura, no había aprendido, había una nueva literatura, por ejemplo. A partir de ese momento tuve la oportunidad de conocer la cuarta generación de Annales, el posmarxismo británico, la escuela de Frankfurt, etc. Es decir... cosas que en los 80 habrían sido absolutamente impensables, dadas las estructuras formativas que existían en las universidades chilenas en ese momento, fuertemente intervenidas por la dictadura militar. De manera que me pareció que el oficio del historiador era una cosa bastante más interesante, estimulante y desafiante de lo que había sido la etapa previa da la formación del pregrado, que había sido más bien plana, aburrida, sin muchos estímulos. Terminé el proceso de formación de posgrado en el año 96, había publicado ya algunas cosas, sobretodo en un sentido bien clásico y estructuralista (altussheriano) de historia económica y social. Había asistido algunos congresos, y el ambiente y la discusión académica me empezaron a llamar la atención. Todo esto me resultó interesante. Seguía trabajando en ese momento en la educación secundaria y algunas de las experiencias que había adquirido en el proceso de formación del posgrado las trataba de transferir o transmitir a la docencia, a la pedagogía que impartía en el liceo. Seguía siendo un momento como de transición, entre un plano de la actividad profesional y otro. Hasta que en 1998 este mismo profesor (René Salinas), que me había llevado al posgrado, a la maestría, me dice... "hay un programa de doctorado en España”, en Murcia en particular, donde él tenia vínculo académico “donde yo creo que a ti te podría ir muy bien... que se yo... te invito a que vayas, podemos buscar algún tipo de apoyo para que no te resulte tan complejo" y me fui. (Risas) Estuve dos años en España, hice un programa de doctorado en 'La historia de la familia en la época moderna' y bueno... esa fue una experiencia impresionante, yo nunca había salido de Chile... en ese sentido fue impresionante en múltiples aspectos: los académicos, los formativo y la experiencia; en el tema del modelo de universidad, o sea el modelo de universidad gratuita, con todos los requisitos propios para la formación académica, amplia disponibilidad de literatura, bibliografía, equipos computacionales, cuerpos académicos con alto grado de formación, espacio de discusión académica en distintos lugares no solamente de esa universidad si no de España y de Europa. Para mí en ese sentido fue un tremendo cambio, una tremenda transformación y me orienté en ese momento al campo 
de la historia social, de preferencia. Fue una suerte de ruptura epistémica muy fuerte con la tradición althusseriana, estructuralista; y un involucramiento cada vez mayor con la sociología histórica y con la historiografía británica en particular. Y en ese sentido, por lo tanto, hubo también un cambio de paradigmas historiográficos que para mí, en ese minuto, fue muy importante. Comencé a asistir a más congresos e ir a congresos internacionales, comenzar a ser parte de las primeras redes de investigadores, tanto en la América Latina como en Europa, con las cuales yo comencé a establecer vínculos más estrechos. Comencé a publicar fuera de Chile.

Me gradué en el doctorado en el 2005, con una tesis que trataba sobre 'familias populares rurales en Chile entre 1750 y 1860'. Un ciclo bastante largo que nos permitió observar elementos de continuidad y ruptura asociados a la construcción histórica de la familia popular en el mundo rural chileno del periodo. Que luego se publicó en el Consejo Superior de Investigación Científica en España, en el CSIC. Y ahí ya había iniciado una carrera académica más convencional o formal en el mundo universitario, yo empecé a impartir clases en la Universidad el año 1996, después de la maestría; pero mí primera jornada completa universitaria fue en 2002, la titularidad en una jornada completa: No sé cómo le llaman acá en Brasil... cuando tomas una cátedra y te dan una jornada de 44 horas en la universidad.

Tempo e Argumento - ¿dedicación exclusiva...?

Igor Alexis Goicovic Donoso - Dedicación exclusiva. Eso es sólo en el 2002, en una Universidad del sur del Chile, la Universidad de Los Lagos (ULA), en Osorno; una universidad pública. Ingrese allí en 2002 y me fui a comienzos de 2006. Ese año, el 2006, trabajé en la Universidad de Concepción (UDEC). Y al año siguiente llegué a la Universidad de Santiago de Chile (USACH), dónde además ahora soy el director del Departamento de Historia. Les podría decir que mí trayectoria académica de alguna otra manera se inaugurase en 1992, se consolida hacia 1998 como preocupación o campo de interés preferente y desde 1998 en adelante se comienza a desarrollar en el sentido estricto, 
pensando en investigar, publicar, construir redes, desarrollar enfoques o perspectivas historiográficas, formar parte de debates y espacios de discusión colectiva, en este campo.

Nosotros en 1998, y con esto ya concluyo esta parte, formamos con este mismo profesor que me llevó a la maestría y que luego me mandó al doctorado (René Salinas), formamos el seminario 'Historia de la violencia' del cual era director él en esa época. Que partió como un seminario orientado preferentemente a la conflictividad doméstica, los conflictos intrafamiliares y los conflictos en el interior de la aldea. Colocando el eje temporal en el espacio del mundo colonial y del mundo del siglo XIX. Pero luego, cuando René fue dejando la responsabilidad del seminario y la fui asumiendo yo... 'Pues yo le torcía la nariz' como decimos en Chile, y orientamos el seminario de Historia de la Violencia hacia el campo de la violencia Política. No lo sacamos absolutamente del campo la violencia social, pero colocamos el énfasis en el campo de la violencia política que hasta ese momento no había sido un tema preferente de investigación. Y a partir de ese minuto yo ya me comienzo a dedicar de manera mucho más sistemática a la investigación sobre la dictadura militar y la insurgencia armada, violencia política, conflicto político, etc. $Y$ en ese seminario hay estudiantes de grado, que hacen sus investigaciones para obtener el grado de licenciado, estudiantes de maestría y estudiantes de doctorado, bueno además de los académicos que formamos parte de ese seminario, que ahora estoy dirigiendo yo, del cual ha participado Luiz Felipe Falcao, Pablo Pozzi... que sé yo... entre otros investigadores, que nosotros invitamos cada cierto tiempo a colaborar con nosotros y hacer proyectos de investigación o en actividades de exposición, de extensión o de publicaciones. Eso!

Tempo e Argumento - Profesor, ¿Cómo es trabajar con la Historia del Tiempo Presente en Chile?

Igor Alexis Goicovic Donoso - Es complejo... A propósito de lo que les he mencionado recién... y esto quizás... les va a sorprender... Yo he tenido oportunidad de conocer en esto últimos diez, quince años, conocer bastante de lo que es el desarrollo historiográfico 
en América Latina y tengo la convicción, no la impresión, la convicción que solamente hay escuelas historiográficas en México, Brasil y Argentina. Escuelas historiográficas en el sentido estricto del concepto. Estoy pensando en los grandes campos de la investigación histórica, la historia económica, la historia social, historia política, la demografía histórica. $\mathrm{Y}$ que en esos campos de investigación fuertemente consolidados, hay además tendencias, orientaciones, escuelas, grupos de investigación con un alto grado de especialización, y publicaciones que son el resultado precisamente de la configuración de ese campo o de esos campos de investigación... Bueno, en Chile eso no hay, eso no existe. Es decir, campos importantes del que hacer historiográfico no tienen ningún desarrollo, no es que tengan poco desarrollo; no tienen ninguno. Por ponerles algunos ejemplos. La demografía histórica dejó de cultivarse hacia mediados de la década de 1970. Tuvo un grado de desarrollo importante con el apoyo de CELADE; pero cuando ese apoyo se perdió, hacia 1975-1976, la demografía histórica desapareció. Nadie hace investigaciones en el campo de la demografía histórica, los archivos parroquiales han quedado tirados, nadie trabaja con esa fuente.

La historia colonial está tremendamente decaída desde el punto de vista de su desarrollo historiográfico. La historia colonial en Chile tiene una larguísima tradición en términos de la incidencia, de la importancia de ese periodo histórico en la configuración de la historia social de Chile, a propósito del peso que tuvo el latifundio, o la gran hacienda en la construcción de la sociedad chilena; pese a ello muy poca gente hace historia colonial. No alcanza para la constitución de una escuela.

También es muy poca la gente que hace historia económica; los seminarios de historia económica suelen no reunir a más de cinco, seis, siete especialistas en Chile y cuando esto se hace a escala latino americana los chilenos tienen una muy baja participación; no baja en calidad, sino baja en volumen.

La historia que tiene que ver más bien con algunas estructuras de la sociedad y el Estado, como la iglesia católica o el ejército, son historias corporativas; es decir curas que hacen la historia de la iglesia, milicos que hacen la historia de las fuerzas armadas. Por lo tanto, suelen ser hagiografías, no trabajos profesionales, desde el punto de vista historiográfico. 
Entonces lo que hay básicamente... (risas) es una preocupación preferente por la historia política y por la historia social. Son los dos campos más fuertes pero, y a propósito de esos dos campos, se debe tener en cuenta que los fondos asignados en investigación en Chile son de dos tipos, solamente de dos tipos. Los que vienen de la propias universidades, son los que nosotros llamamos los 'proyectos internos'; es decir financiamiento que la universidad pone a disposición de los investigadores, para cada investigación, que suelen ser montos muy bajos... muy... muy bajos, casi simbólicos. Para que se hagan una idea... un fondo anual de más o menos dos mil quinientos dólares para investigar... es decir en Chile con dos mil quinientos dólares al año es muy poco lo que se puede hacer. $\mathrm{Y}$, además, son fondos concursable, es decir no es que tú lo pides y te lo asignan; hay que concursar por un monto global del cual a ti te tocan dos mil quinientos dólares al año. Con eso es muy poco con lo que se puede hacer. Luego están los fondos del Estado. Los proyectos regulares de FONDECYT, como les llamamos en Chile; que también son fondos concursales. Normalmente en el campo de la historia se asignan once proyectos al año. Yo tengo un proyecto FONDECYT de esa naturaleza de tres años, y los montos asignados son más o menos del orden de los treinta y dos mil dólares (US\$32.000) al año. Ahí sí ya se puede investigar. Pero se asignan en la historia entre once y doce proyectos anuales, es decir... el cuerpo de investigadores en el campo de historia en Chile es un cuerpo muy reducido, muy pequeño y ese es el factor, en mi juicio, que inhibe o que no permite un desarrollo sistemático de los distintos campos investigativos y el grueso de los que se dedican a la investigación con subsidios estatal o con subsidios internos de las universidades lo hace en la historia política y en la historia social; y en ese contexto un grupo específico de los investigadores que trabajan en historia política, se dedican a la historia del tiempo presente. Por lo tanto el impacto, en términos de volumen, de las investigaciones referidas a historia del tiempo presente es muy acotado, muy pequeño y, por lo tanto, comparativamente (vuelvo a insistir) con México, Brasil o Argentina, no admite muchas comparaciones. Es un campo en construcción, por denominarlo de alguna manera; donde no son más de diez o doce los académicos dedicados preferentemente al mismo. Pero sí, quizás ahí está la ventaja, con un cuerpo de estudiantes de pregrado y posgrado bastante más amplio, que multiplica las 
posibilidades de proyección de este campo. Es un campo que está generando interés, preocupación, pero un campo en construcción, un campo en desarrollo. No se hagan expectativas. (risas).

Tempo e Argumento - Hablamos ahora... en la actualidad... ¿cuáles son los temas dentro de la historia política de Chile donde se percibe mejor interés para los investigadores políticos?

Igor Alexis Goicovic Donoso - Yo diría que hay dos temas preferidos. Uno en el campo de las organizaciones políticas y dentro de ese campo, como dos tendencias, una tendencia más clásica o convencional y que tiene que ver con los programas, las orientaciones, los diseños tácticos, las estrategias, etcétera; y otra que tiene que ver más bien con el campo del militantismo, de la subjetividad, de las culturas políticas, las sociabilidades políticas. Son las dos tendencias que uno puede observar.

Y el otro el de la dictadura militar. $Y$ en ese sentido fuertemente asociado a uno de los elementos que marca, de cierta forma, o que hace distintiva la dictadura militar chilena, como es la represión política. La dictadura militar no como lo que efectivamente fue, un complejo de proyectos, transformaciones, orientaciones y diseños, que tiene que ver con lo económico, lo social y lo político, sino que con sólo uno de los aspectos que la distingue, pero que no la agota, que es el tema de la represión política.

Esos son los dos aspectos fundamentales que uno puede observar en el campo de la historia política reciente en Chile. Hay algunos historiadores que van más atrás y observan el desarrollo del Estado, la construcción de Estado, las elites políticas en el siglo XIX, algunas rupturas políticas y los contenciosos de comienzo del siglo XX. Pero ese tipo de investigaciones ha tenido menos desarrollo que esto que les estoy mencionado ahora; es decir, el tema del conflicto y la violencia política de fines de la década de 1970 y hasta comienzos de la década de 1990, que es donde se concentra la preocupación preferente. 
Tempo e Argumento - Nos damos cuenta de que se utilizan en algunos de esos textos la perspectiva de historia comparada. ¿En qué medida esa práctica ha traído nuevos conocimientos sobre la historia de Chile?

Igor Alexis Goicovic Donoso - Bueno... Yo les mencionaba que el desarrollo historiográfico en estos campos es relativamente reciente, está recién en proceso de construcción, y uno de sus déficits es la construcción de redes académicas a escala latinoamericana y a escala internacional. Los intelectuales chilenos todavía somos endogámicos; no salimos mucho hacia el extranjero, no solamente no salimos físicamente, sino que no establecemos vínculos muy estrechos con nuestros pares de la comunidad académica latinoamericana o regional. Algunos si lo hemos venido haciendo recientemente y en ese sentido los proyectos de CLACSO, los grupos de trabajo de CLACSO, han jugado, a mi juicio, un rol clave, fundamental. Nosotros tenemos este grupo de trabajo, del cual es parte Luis Felipe Falcao, por ejemplo y Pablo Pozzi. Desde hace ya cinco años tenemos reuniones periódicas; hemos desarrollado publicaciones conjuntas, yo he tenido la oportunidad de hacer trabajos de similar naturaleza con colegas de Argentina, Bolivia, Perú y de España, en este último tiempo, y eso te permite varias cosas. Te permite, por una parte, desarrollar procesos de actualización a nivel teórico metodológico, que es fundamental en este campo de la historiografía. Se está más al día en lo que son los enfoques teóricos y los diseños metodológicos que se están aplicando en historia del tiempo presente o en historia política. $Y$ por otro lado te permite, a propósito de la pregunta de ustedes, establecer marcos comparativos en la investigación sobre cuestiones en común, como pueden ser las dictaduras militares o las prácticas de la militancia política o de la cultura política. Pero ‘ojo', es importante entender que esos diseños comparativos no tienen que ser necesariamente por homologación o por afinidad, sino que también pueden ser por distinción, por diferenciación, porque si hay algo que hemos de lograr entender en este último periodo es que los procesos históricos de la región, si bien manifiestan ciertas tendencias generales que son comunes, como las dictaduras de seguridad nacional, los procesos políticos a los que dan origen y las proyecciones que esos procesos tienen hasta el tiempo presente, no es menos efectivo poseen rasgos internos bien distintos. En ese sentido las experiencias acumuladas son 
positivas y auguran trabajos comparativos de mayor densidad y más conclusivos. Yo diría que en este momento todavía hemos estado instalando temas, pero hay una etapa que no hemos desarrollado, que es la de establecer conclusiones y tendencias generales respecto a las investigaciones que hemos desarrollado. Probablemente los próximo cinco, seis años, ya deberíamos llegar a ese tipo de conclusiones... en eso estamos.

Tempo e Argumento - También observamos que sus estudios se concentran en los contextos de desarrollos y prácticas violentas y opresivas. ¿Cuál es su punto de vista sobre el crecimiento de las violencias en varias ciudades de América Latina, incluso después de las dictaduras?

Igor Alexis Goicovic Donoso - Un tema súper complejo... mira, para hacer un ejercicio muy sintético, quizás demasiado esquemático, voy a señalar tres cuestiones que me parecen que son importantes. Primero que la violencia es un componente estructural de las relaciones sociales y políticas en América Latina, no solamente en dictadura, sino que también en sistemas no dictatoriales. El régimen oligárquico durante el siglo XIX fue un régimen fundado, entre otras cosas en la violencia estructural, que tiene que ver con la explotación, la exclusión, la discriminación y la represión. En el caso del Brasil los levantamientos de esclavos y la represión de los mismos son una expresión manifiesta de este fenómeno. La ocupación de la Patagonia en Argentina y en Chile, a mediados del siglo XIX, o la expansión de la frontera agrícola como se le va a denominar en diferentes países de la región, a partir del año 1870, 1880, también es manifestación de lo mismo. Y los procesos, a su vez, de transición del régimen oligárquico hacia los regímenes autoritarios de naturaleza dictatorial o hacia regímenes democráticos de tipo plutocrático, están fundados, también, en violencias institucionales y en violencias estructurales. La represión del movimiento obrero a comienzos del siglo XX, en toda la región, entrega imagen concluyente de ese mismo fenómeno. Por lo tanto la primera cuestión que me interesa destacar es que la violencia no es un componente que acompaña exclusivamente a las dictaduras militares. En dictadura tiende a ser más explícita, más evidente, más manifiesta, más desembozada. Pero en ningún caso es exclusiva de este tipo de regímenes. Esa es una primera cuestión. 
Y eso, a su vez, remite a la naturaleza patriarcal de las construcciones sociales latino americanas; tiene otras representaciones de la violencia social, de las cuales el feminicidio, la violencia intra doméstica o la violencia familiar son componentes absolutamente recurrentes y cotidianos. $\mathrm{Y}$ este tipo de violencias se proyecta hasta el tiempo presente. Por ejemplo, en las elecciones presidenciales en Brasil (2014), uno de los spots de Dilma Rousseff, uno de los aspectos en los cuales se coloca énfasis es en los compromisos del gobierno para contener el fenómeno de la violencia doméstica. Y este es un fenómeno que no solamente se da en Brasil, si no que en general en toda la región; y que tiene que ver, reitero, con un legado de la cultura patriarcal, que no logra ser erradicado y, por lo tanto sigue reproduciendo este tipo de conductas.

O aquellas violencias asociadas a la conducta delictiva, transgresora, criminal, que en sus diferentes construcciones históricas se expresa, también, como un fenómeno violento recurrente. Hoy día, por ejemplo, el narcotráfico, los secuestros y los asesinatos de quienes se oponen a estas mafias. El secuestro y asesinato de 43 jóvenes en México (septiembre de 2014), es una de sus expresiones contemporáneas más aberrantes de este tipo de violencias. De manera tal que las violencias estructurales, las violencias políticas y las violencias sociales son un componente histórico en las relaciones sociales y de poder en la región, esa es una primera cuestión.

Se agudizan, en segundo lugar, durante los regímenes dictatoriales. En especial en la dictadura de seguridad nacional que aplican la estrategia de contrainsurgencia, que en el escenario de guerra fría, construye la imagen del “enemigo interno": El comunismo. En este esquema Brasil fue una escuela para la región. Pero los problemas de la dictadura no concluyen con las dictaduras; se prolongan hacia las transiciones, en la medida en que los problemas heredados de la dictadura, derivados de las transformaciones económicas, de los ajustes sociales, de los cambios culturales, de la extensión de las dictadura que tanto en Chile como en Brasil se acercan a las dos décadas, son muy profundos. Son dos generaciones, en definitiva, las que se forman en el contexto dictatorial. $\mathrm{Y}$ eso, evidentemente, tiene efectos sociales y culturales profundos. $Y$ las transiciones no necesariamente desmontaron todo ese tipo de construcciones sociales y culturales 
heredadas de la dictadura, por lo tanto los problemas asociados a la dictadura en algunas circunstancias, tienden a reeditarse posteriormente. Y quizás ahí uno de los campos más interesantes, a propósito de la legitimación de la violencia como instrumento de acción social y política, tiene que ver con el concepto de impunidad, es decir si en un momento determinado, la dictaduras cometieron violaciones a los Derechos Humanos y esas violaciones a los Derechos Humanos no fueron castigadas, la sociedad entiende que el delito o la violencia, pueden ser un objeto, una herramienta, un instrumento al cual se puede recurrir y que no necesariamente supone o conlleva un castigo. Puede ser como tú dices, 'una herramienta aceptada', con un cierto grado de valoración, legitimación, dentro del cuerpo de la sociedad.

La transformación cultural, en lógica neoliberal, permea a las sociedades latinoamericanas y restituye al sujeto en esta condición que Hobbes denominaba como ‘la capacidad de depredación’ de los hombres. Es decir, la violencia se convierte en una herramienta, un instrumento; yo la ejecuto y por lo tanto me da lo mismo, porque me importa 'un carajo' lo que pueda estar ocurriendo en el entorno.

Pero por otro lado las dictaduras militares fueron eficientes en desconstruir tejido social, tejido asociativo; esta idea, estas nociones de construcción solidaria del entorno y del espacio social; los sindicatos, las agrupaciones vecinales, incluso los mismos partidos políticos populares, fueron destruidos. El caso más evidente es Chile. Y al desaparecer estas estructuras de mediación entre el Estado y la sociedad, al desaparecer, al difuminarse, al perder legitimidad, perder fuerza, se abre nuevamente un espacio para la acción individual. Y por lo tanto para la acción directa o para la acción violenta. En ese sentido la desaparición de la izquierda social y política se convierte en un antecedente de esto que ustedes ven, de esta escalada de violencia que es posible observa en la ciudad latinoamericana.

La izquierda operaba como un mecanismo de contención de esta violencia social; pero al desaparecer o al perder fuerza esta izquierda, desaparece la mediación y por lo tanto las formas violencia social adquieren una mayor presencia y por lo tanto una mayor incidencia. Para poner un caso, a propósito una experiencia chilena. El Partido Comunista 
históricamente ha tenido fuerza e influencia en los barrios obreros, en especial de Santiago; incluso durante la dictadura militar. Es más, el brazo armado del Partido Comunista, el Frente Patriótico Manuel Rodríguez, tenía control territorial sobre esos barrios. Y en esos barrios no había narcotráfico, no existía el narcotráfico. Desapareció Frente Patriótico Manuel Rodríguez, despareció la influencia del PC y el narcotráfico tomó el control de esos barrios. O sea ahí el problema no es la ausencia-presencia de las fuerzas policiales, sino que es la ausencia, en este caso, de la organización política de izquierda que lograba mediar o administrar ciertos problemas. Hay una figura emblemática que ahora es alcaldesa, Claudina Núñez que era dirigente poblacional en un barrio de Santiago, que durante la dictadura nunca pudo ser represaliada o reprimida por la dictadura porque la protegía el Frente, pero en la década de 1990, es decir, acabada la dictadura e iniciaba la democracia, ella tuvo que colocar un 'recurso de amparo' en los tribunales justicia porque el narcotráfico la había amenazado de muerte, y ya no existía el Frente para que la protegiera, o sea tenía que recurrir a quienes la habían perseguido (la policía), para que la protegieran del crimen organizado. Ese es un poco a mi juicio, en términos casuísticos, una de las expresiones de lo que ha estado ocurriendo en Chile.

Quizás, en alguna medida, también sirva como modelo para analizar la situación de violencia en algunas ciudades latinoamericanas. No sólo como expresión de la debilidad del Estado frente a este tipo de fenómenos, sino también como expresión de la ausencia de agencias de mediación que, en otras épocas, contenían este tipo expresiones.

Tempo e Argumento - Profesor en su opinión los modelos existente de la democracia en la América Latina, después de la democratización ¿son modelos que han fracasado?

Igor Alexis Goicovic Donoso - Hay dos formas de acercarse a este tema. Podemos apreciarlo desde la perspectiva de los sectores populares. Se entiende que en la última fase de los procesos dictatoriales se generaron muchísimas expectativas entre los sectores populares, no solamente por el termino de las arbitrariedades, los abusos y la represión, sino que, también, en términos de que la transición de la dictadura a la democracia debía, necesariamente, expresarse en más derechos; y esta condición de 
mayores derechos, debía expresarse en la mejora de las condiciones materiales de vida y de trabajo de la población. Y los resultados de las transiciones de las dictaduras a la democracia no se expresaron necesariamente de esa manera. No estoy pensando sólo en la dictadura militar Chilena, sino que, en alguna medida, también en lo que ocurrió en Brasil, especialmente en las administraciones de Fernando Collor de Mello, Itamar Franco y Fernando Henrique Cardoso, en donde las expectativas de la sociedad brasileña de avanzar de manera más o menos acelerada y sostenida hacia procesos de mayor equidad se vio frustrada. Por el contrario, estas sociedades sean visto enfrentadas a profundas reformas neoliberales. Los gobiernos democráticos, en la década de 1990, terminaron adoptando las directrices del Consenso de Washington. La Democracia, por lo tanto, aparece asociada a transformaciones que resultan más abusivas y más arbitrarias que la misma dictadura. Entonces, mirada desde esa perspectiva podría decir "esto fue un fracaso". La transición ha fracasado de acuerdo con lo que eran las expectativas de mayor empoderamiento y de mejor satisfacción de ciertos requerimientos fundamentales de la población.

Pero si lo miramos desde otra perspectiva, de la perspectiva de las elites de poder, que en su momento apoyaron y respaldaron a la dictadura y que probablemente vivían con angustia o con aprensión la transición a la democracia, estas transiciones han demostrado que esas elites de poder no tenían nada que temer. Porque los modelos políticos, económicos y sociales que se van configurando, construyendo, en las etapas de la transición no amagaron, no resintieron, sustantivamente, la estrategia de poder de esta clase dirigente. Muy por el contrario, las democracias garantizaron mejores condiciones, por una parte para la inversión extrajera, y por otro lado para la estabilidad de las estrategias de crecimiento económico, como lo han demostrado hoy día los casos de Brasil, de Chile y de Perú. Son los países que en este último tiempo, estoy pensando en las últimas dos décadas, ha crecido más sostenidamente, llegando, en el caso brasileño a ubicarse entre las economías emergentes más importante en escala global; y en el caso de Chile, no teniendo el mismo peso que la economía brasileña, es una de las economías más ordenadas a escala latinoamericana. 
Por lo tanto en ese esquema o de acuerdo con ese enfoque los procesos de transición a la democracia no amagaron, ni afectaron, los intereses de los proyectos de desarrollo, de crecimiento de las clases dirigentes, sino que se convirtieron, por el contrario, a propósito de la estabilidad de los regímenes democráticos, en un factor que contribuye mucho más eficientemente que la dictadura a incrementar los niveles de inversión extranjera y local y a mejorar las condiciones estructurales para el crecimiento económico. Estos regímenes entre otras cosas, ha sido más eficientes en el control social, porque no han tenido que recurrir a la represión para generar control social, o por lo menos no han recurrido a la represión desembozada, arbitraria o brutal como lo hicieron las dictaduras; sino que, por lo contrario, han administrando y regulando los conflictos sociales y políticos. $Y$ de esa manera al dar mayor estabilidad al sistema político evidentemente nuestros países se convirtieron en países más atractivos para la inversión económica. Mirado desde esa perspectiva la transición hacia la democracia ha sido tremendamente positiva, sin lugar a dudas. Por lo tanto depende de donde uno se instala para poder evaluar y poder calificarla. A los académicos también nos ha ido muy bien.

\section{Tempo e Argumento - ¿Cómo?}

Igor Alexis Goicovic Donoso - A los académicos también nos han ido muy bien (risas).

Tempo e Argumento - Para finalizar... En un mundo de cambio constante... ¿para usted cuál es la función, o la utilidad de la historia?

Igor Alexis Goicovic Donoso - Tema complejo...(risas) Esta es una opinión estrictamente personal y por lo tanto no es corporativa, ni gremial. Los historiadores, como profesionales, como investigadores y como docentes, tenemos proyectos, expectativas, intereses que son tremendamente particulares; y no todos los historiadores pensamos lo mismo de todo esto, del campo disciplinario que nosotros cultivamos. Yo creo que hay tres cuestiones que son fundamentales, por lo menos para mí. Una tiene que ver con una noción, si ustedes quieren clásica, casi conservadora respecto a la historia, que es sobre 
la valoración del conocimiento, no necesariamente la funcionalidad del conocimiento. Yo creo que es necesario investigar y conocer del pasado porque es necesario conocer el pasado, en cuanto a aprendizaje. Dicho de otra manera, la satisfacción propia de conocer otros procesos y otros fenómenos históricos, por el solo hecho de incorporar un mayor bagaje de conocimiento sobre esas experiencias a las cuales nosotros nos acercamos con nuestra investigación. Es decir, placer, satisfacción de aprender más sobre determinado fenómeno.

Hay un segundo campo que es lo que ustedes instalaban al comienzo de la conversación, que es el campo pedagógico. Yo creo que ese es un campo imprescindible, un campo fundamental, porque como lo señalaban los clásicos la historia es "magister viatel” , "es maestra de la vida" y, en cuanto tal, al aprender de la historia no solamente aprendemos en el sentido convencional, a no cometer los mismos errores (igual los cometemos), sino que a su vez vamos delineando y vamos definiendo horizontes utópicos a los cuales queremos llegar. En ese sentido al aprender del pasado, estoy reflexionando pedagógicamente, y al hacerlo también vamos adelantando nuestros proyectos de futuro, vamos acercándonos a nuestro proyecto de futuro. $Y$ ahí es donde yo veo la principal dificultad que tiene la academia; estoy pensando en el cuerpo de investigadores, pesquisidores, docentes. A nivel de educación superior no hemos sido capaces de generar procesos eficientes, tanto de transferencia, como de retroalimentación, con las experiencias pedagógicas. $Y$ ahí hay una especie de fractura, hay una interrupción, entre la producción de conocimiento científico en las universidades y el desarrollo de los procesos pedagógicos que desarrollan los maestros en los establecimientos educacionales. $\mathrm{Y}$ esa fractura, que es bastante extendida y que yo creo que requiere sutura, hay que remediarla y en ese sentido no solamente se necesitan espacios de reflexión, como éste, fuertemente orientados hacia los procesos pedagógicos; también se necesita incrementar el intercambio académico entre pares, ampliar los espacios de debate y discusión; y en ellos debiera ser partícipe, participe protagónico, el maestro que se desempeña a nivel primario y secundario. De lo contrario el conocimiento historiográfico puede ser muy avanzado, muy sistemático, muy riguroso, y estar contenido en un montón de textos y se va a quedar ahí y no va a tener ninguna 
posibilidad de ser cotejado, contrastado y por lo tanto reciclado con la experiencia concreta; esa contrastación se verifica en el área pedagógica; ese es el tema fundamental. Y el tercero es el campo más propiamente político. Que nos interpela como ciudadanos; tiene que ver que nosotros a través de nuestras investigaciones, nuestra práctica profesional; tiene que ver con cómo "vamos tomando partido", vamos escribiendo, vamos posicionándonos, vamos emitiendo opinión, y por lo tanto comenzamos a ser sujetos del debate político contingente. La historiografía tradicional, conservadora, siempre ha pretendido que tratemos de apegarnos a la historia más clásica, más convencional, más antigua, porque de ahí se contaminaría menos la percepción del historiador; la historia del tiempo presente muestra todo lo contrario, el historiador tiene que estar instalado en la contingencia y reflexionando respecto al pasado desde la contingencia. Igualmente en el caso de Chile, y esto estoy pensando más colectivamente, en términos de un sector de la historiografía chilena, la detención de Pinochet en Londres en 1998, fue clave, porque nos obligo como historiadores a pronunciarnos sobre nuestra historia reciente; nos obligó no solo a investigar sino a emitir un pronunciamiento político. Y de ahí salió un documento que se llama el 'Manifiesto de los historiadores', que precisamente rayo la cancha de la historiografía chilena, respecto a cómo nos posicionábamos nosotros sobre nuestro pasado inmediato, sobre las transformaciones económicas, sociales, sobre las violaciones a los Derechos Humanos, sobre la situación de Pinochet. En el proceso de transición a la democracia, ustedes no sé si lo saben, Pinochet seguía siendo comandante en jefe del ejército y luego senador vitalicio en el Parlamento. Eso era algo espurio, estábamos transitando la democracia y teníamos el dictador metido al medio del proceso de transición a la democracia. Ese es un elemento que en definitiva, lo reitero, nos lleva a los historiadores a tomar postura, a tomar partido y en ese sentido a construir un compromiso más evidente, más concreto. No sólo con la democracia, en el sentido genérico del concepto; como ustedes decían recién 'no es ir y votar', sino que asumir un compromiso directo con el empoderamiento, en este caso con los sectores populares y con los contextos de transición a la democracia; ser más explícitos, en ese sentido, respecto de nuestros pronunciamientos. $Y$ en eso estamos también. 
Pesquisas em história, violência e política no Chile - Uma conversa com o Prof. Igor Alexis Goicovic Donoso

Tempo e Argumento - Bueno es eso... muchísimas gracias profesor, nos ha ayudado mucho.

Igor Alexis Goicovic Donoso - Encantado.

Universidade do Estado de Santa Catarina - UDESC

Programa de Pós-Graduação em História - PPGH

Revista Tempo e Argumento

Volume 07 - Número 14 - Ano 2015 tempoeargumento@gmail.com 